\title{
Disseminating science: an illustration of present and future scenarios
}

\author{
Giulio Zuanetti, MD \\ AboutScience Srl, Milano - Italy
}

\begin{abstract}
The last years have witnessed an unprecedented use of open access in scientific publishing to disseminate science beyond the borders of the academic and research community. In this article, the classic paywall and the more recent open access scenario of publishing are summarized in four key images that may be helpful in illustrating opportunities and challenges for researchers and academics. Combining their efforts with those of institutions, journalists and life science executives to promote proper science and tackle pseudoscience should be a key priority for the next decade and beyond.
\end{abstract}

Keywords: Academic communities, Open access publishing, Research communities, Science dissemination

\section{Introduction}

During the last decade scientific publishing has progressively evolved, leading to a major increase in the number of open access and preprint articles, a trend further accelerated by the Covid-19 pandemic (1).

The need to disseminate science beyond the borders of the academic and research community is becoming a number one priority as illustrated by the new European Horizon program where dissemination strategy is one of the keys for a successful funding of the projects (2).

In this article, I try to summarize in four simple images some of the key concepts underlying the need for disseminating science.

\section{Disseminating science in a paywalled scenario}

Until about a decade ago, the vast majority of original research was published in academic journals that were available only upon subscription to a limited audience of people working in research institutions and hospitals whose libraries could afford to pay for the journal subscriptions.

Figure 1 represents such a scenario where the information is kept within solid walls of an imaginary fortress.

Two "sources" are depicted: the one on the left represents a manuscript published on a top journal, as indicated

Received: April 19, 2021

Accepted: May 20, 2021

Published online: August 5, 2021

Corresponding author

Giulio Zuanetti

AboutScience Srl

Piazza Duca D’Aosta, 12

20124 Milano MI - Italy

giulio.zuanetti@aboutscience.eu by a very resistant dam (representing an extremely selective peer review process). Once the dam is passed and the article is accepted and published, the new data make an impact represented by the cascade.

The source on the right represents a less prestigious journal in the same area. The dam is less selective and the accepted manuscript has a lower impact.

In both cases, the effort of the researchers has been focused on getting through the dam, that is, pass peer review, and the impact is in large part limited to the small circle of academia and research community. The real stakeholders who would benefit from this new evidence (i.e., clinicians, citizens, patients and other end users) are far away in the horizon without easy first-hand access to the source.

\section{Disseminating science in the open access era}

The advent of open access is dramatically changing the above scenario. Most importantly, the wall separating academia from the other stakeholders has disappeared. Clinicians, citizens, patients and other end users have the opportunity to read and learn the new evidence at the same time as the small network of researchers.

Obviously, in most cases, it is impossible for individuals without the appropriate background to thoroughly understand original new evidence. However, in very specific areas such as rare diseases, patients and caregivers often become real "experts" and the availability of new evidence allows them to "be at par" with physicians and healthcare professionals.

In such a scenario there is an immediate opportunity to be exploited by the scientific community: that is, to disseminate more effectively the new evidence to the larger community of clinicians and patients alike.

This is represented in Figure 2 by the more impetuous cascades compared to the ones in the paywalled scenario. 
CLINICIANS

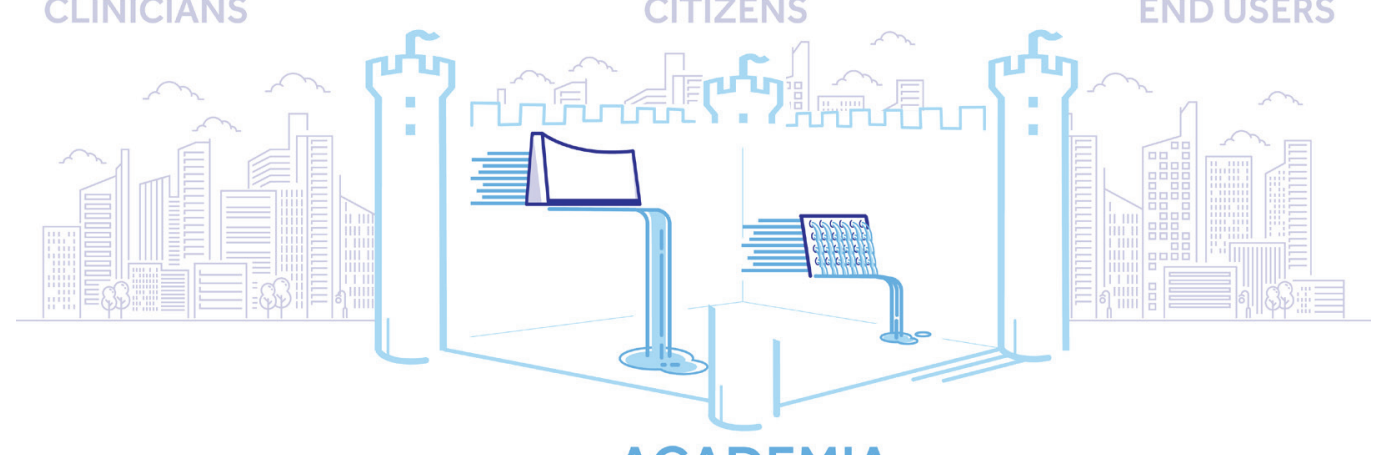

Fig. 1 - The paywalled scenario.
Several actions have the potential to increase the dissemination of new evidence, including: (a) writing the manuscript using Academic Search Engine Optimization (ASEO) (3), (b) adding a lay summary of the findings to the final manuscript, (c) illustrating results with infographics, (d) starting and populating a blog geared toward a general audience.

Of note, open access allows researchers to "make an impact" even if their work is not published on a top journal, since the possibility to freely share the full text of the article and a clever use of social networks such as Twitter and
Linkedln exponentially increases the opportunity to increase the awareness of the article. Interestingly, this is now measured by a number of pure non-bibliometric indexes such as Altmetric (4) or hybrid indexes such as Plum X Metric (5).

Alongside the opportunities, this evolving scenario brings new challenges. In an environment in which new evidence is generated and published at an unprecedented rate, the field of disseminating science becomes ever more competitive. Thus, being extremely active in promoting the researcher's own work is no longer a commodity but a real need.

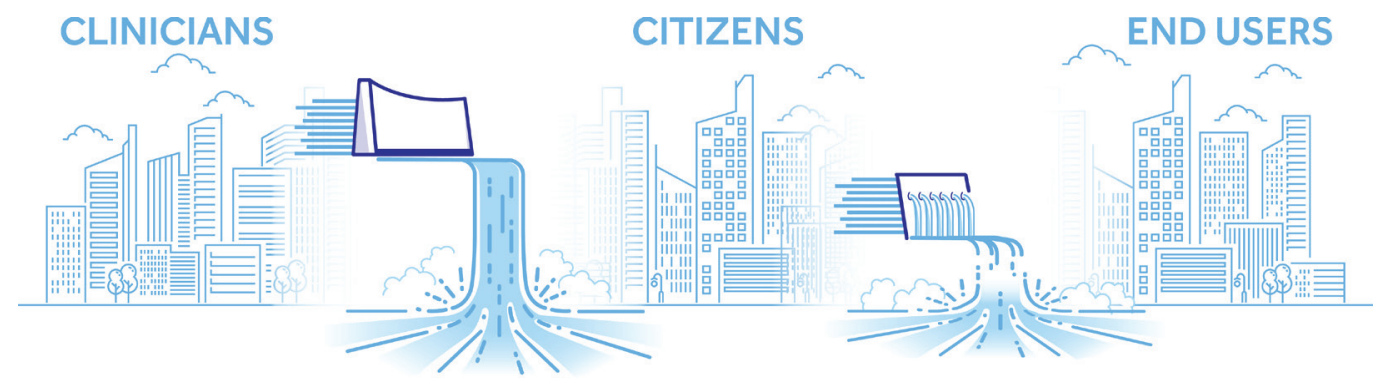

Fig. 2 - The open access environment.

\section{ACADEMIA}

There is a flip side to it, as open access is contributing to another form of inequity: in the paywalled scenario, academics in countries where they couldn't afford subscriptions couldn't read the full text of relevant new evidence. Now, despite individual initiatives by publishers to overcome this challenge, they often can't afford the cost of open access (article processing charges or APCs) and thus struggle to publish.
Last but not least, there is also a dark side to it. In an open access environment, predatory publishers and hijacked journals can flourish (6), making them an ideal substrate to disseminate "pseudoscience," the main source of fake news that continues to pollute science nowadays. This is represented in Figure 3, by the source with the brown water flowing freely with no peer reviewer filter whatsoever, representing a complete lack of peer review by these journals.

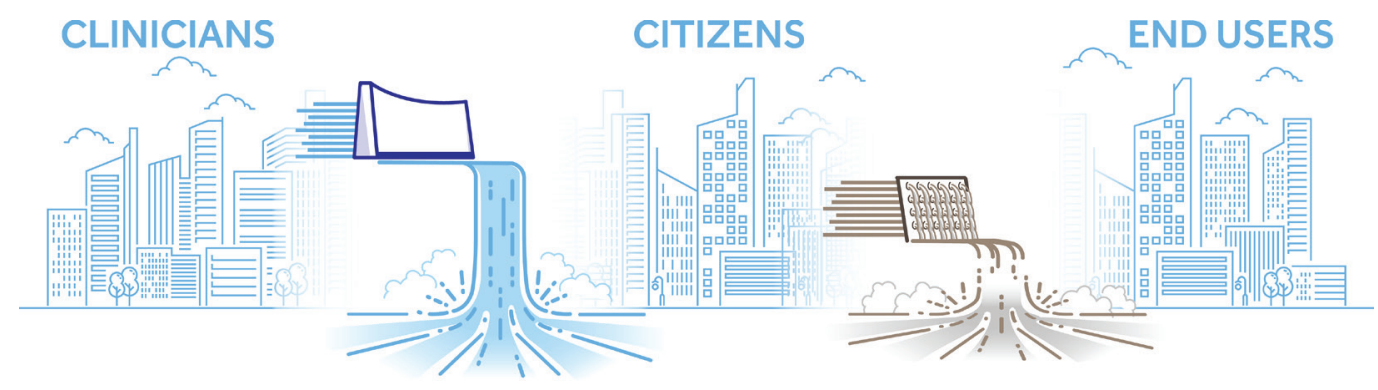

Fig. 3 - The pollution of science by predatory publishers. 


\section{The growing importance of a proper lay press coverage of scientific data}

Among the end users of scientific data in open access, it is very clear that journalists, with or without a scientific background, must step up the game and make sure that their interpretation and reporting of new data is appropriate and balanced. A best case example is the website The conversation where articles are written in a format and tone of voice very appropriate for a larger audience and relevant topics, such as how to convey data to public, are constantly covered (7). Unfortunately, it is difficult for lay press to be always balanced, since the "share of voice" of internet traffic on websites is more easily obtained by pushing the boundaries of how new data are reported and conveyed.

\section{The key role of institutions, scientific associations and life science industry}

In recent years, the focus of institutions and scientific associations has been to make science open and transparent to the research and academic community, with the increased use of tools that make plagiarism, inappropriate authorship or use of patient data more difficult and rare.

This focus should now be accompanied by efforts geared on one side at minimizing the impact of "pseudoscience" and on the other at maximizing a correct and timely dissemination of science. Figure 4 summarizes this concept. In a closed environment (left part), both in the case of top (A) or other (B) journals, the dissemination of science is in itself limited but the threat from predatory journals $(C)$ is minimal or nonexistent. In an open access environment, there is a huge opportunity to increase the speed and reach of science dissemination. On the other hand, the threat from predatory journals becomes a real one. Paradoxically, although there have been several attempts in the past to identify and list predatory journals, from the famous Beall's list (8) to the limited attempt of Stop Predatory Journals (9) the only list of predatory publishers continuously updated is the Cabell's list, which is available only through a subscription fee. This hinders proper efforts to tackle the problem at its roots.

Disseminating proper science and tackling pseudoscience is a key priority in the decades to come. I hope that the figures in this article can be used in presentations to illustrate these challenges to all stakeholders involved in a simple and effective way.

\section{Acknowledgments}

I am deeply thankful to Marco Marsala, HPS-AboutPharma Art Director, for the illustrations of this article and to Yvonne Campfens and Giacomo Bellani for their very helpful comments.

\section{Disclosures}

Conflict of interest: The author declares no conflict of interest. Financial support: This research received no specific grant from any funding agency in the public, commercial or not-for-profit sectors.

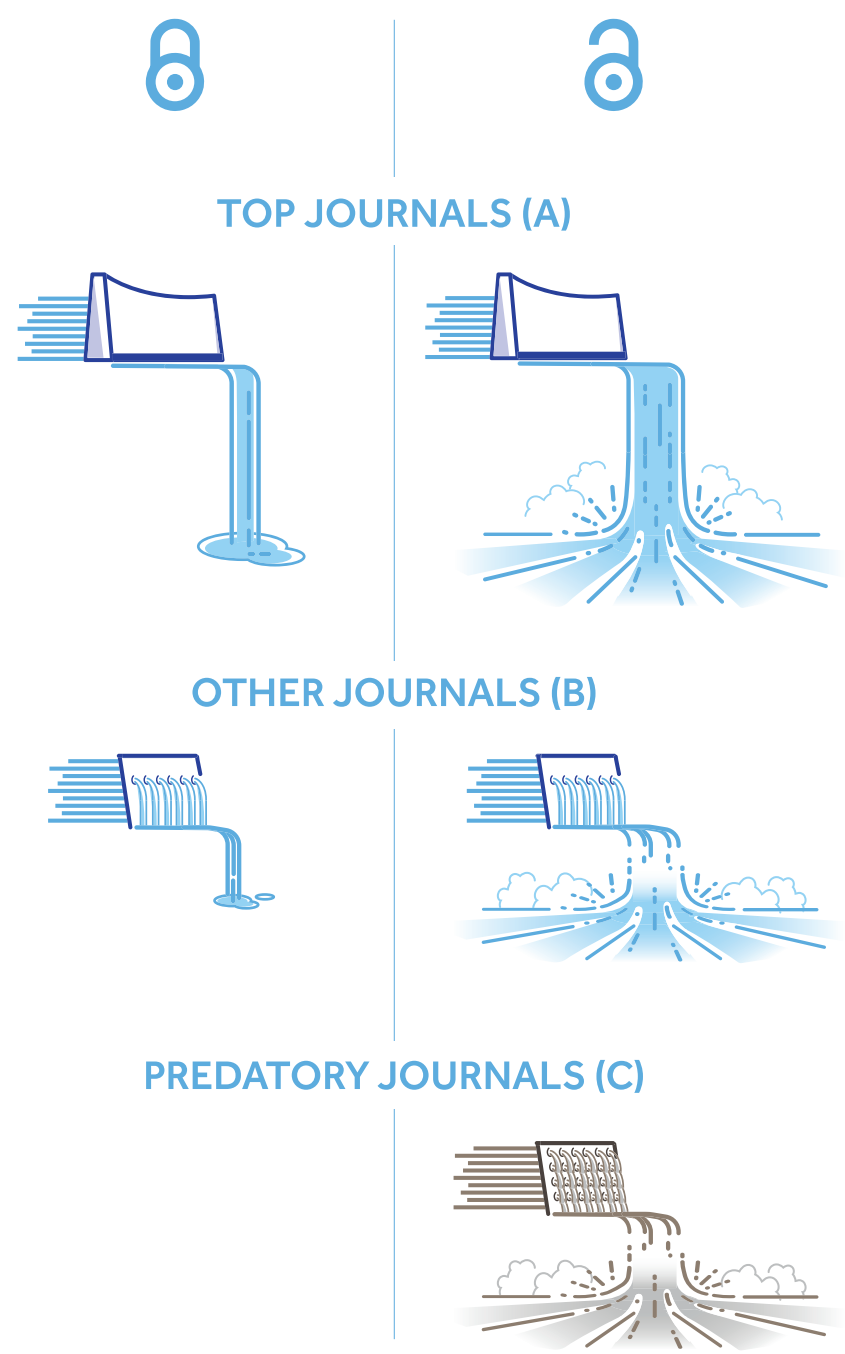

Fig. 4 - Top journals (A), other journals (B) and predatory journals (C) in a paywalled and open access environment.

\section{References}

1. Fraser N, Brierley L, Dey G, et al. The evolving role of preprints in the dissemination of COVID-19 research and their impact on the science communication landscape. PLoS Biol. 2021;19(4):e3000959. CrossRef PubMed

2. A new horizon for Europe. Impact assessment of the 9th EU framework programme for research and innovation. Online Accessed July 2021.

3. Schilhan L, Kaier C, Lackner K. Increasing visibility and discoverability of scholarly publications with academic search engine optimization. Insights. 2021;34(1):6. CrossRef Accessed July 2021.

4. Who's talking about your research? Online Accessed July 2021.

5. Plum Analytics. About Plum X Metrics. Online Accessed: July 2021.

6. Grudniewicz A, Moher D, Cobey KD, et al. Predatory journals: no definition, no defence. Nature. 2019;576(7786):210-212. CrossRef PubMed

7. The conversation. Academic rigour, journalistic flair. Online Accessed July 2021.

8. Beall's list of potential predatory journals and publishers. Online Accessed July 2021.

9. Stop Predatory Journals. Online Accessed July 2021. 